\title{
Surgical ergonomics - Analysis of technical skills, simulation models and assessment methods
}

\author{
Sotiris C Papaspyros ${ }^{1 *}$, Ashok Kar ${ }^{1}$, David J O'Regan² \\ From World Society of Cardiothoracic Surgeons 25th Anniversary Congress, Edinburgh \\ Edinburgh, UK. 19-22 September 2015
}

\section{Background/Introduction}

Over the past two centuries the surgical profession has undergone a profound evolution in terms of efficiency and outcomes. Societal concerns in relation to quality assurance, patient safety and cost reduction have highlighted the issue of training expert surgeons. The core elements of a training model build on the basic foundations of gross and fine motor skills.

\section{Aims/Objectives}

We provide an analysis of the ergonomic principles involved and propose relevant training techniques. We have endeavoured to provide both the trainer and trainee perspectives.

\section{Method}

This analysis is structured into four sections: 1) Preoperative preparation issues, 2) technical skills and instrument handling, 3) low fidelity simulation models and 4) discussion of current concepts in crew resource management, deliberate practice and assessment.

\section{Results}

Rehearsal, warm-up and motivation-enhancing techniques aid concentration and focus. Appropriate posture, comprehension of ergonomic principles in relation to surgical instruments and utilisation of the non-dominant hand are essential skills to master. Low fidelity models can be used to achieve significant progress through the early stages of the learning curve. Deliberate practice and innate ability are complementary to each other and may be considered useful adjuncts to surgical skills development.

${ }^{1}$ Cardiothoracic Surgery Department, Royal Infirmary Edinburgh, Edinburgh, EH16 4SA, UK

Full list of author information is available at the end of the article

\section{Discussion/Conclusion}

Safe medical care requires that complex patient interventions be performed by highly skilled operators supported by reliable teams. Surgical ergonomics lie at the heart of any training model that aims to produce professionals able to function as leaders of a patient safety oriented culture.

\section{Authors' details}

${ }^{1}$ Cardiothoracic Surgery Department, Royal Infirmary Edinburgh, Edinburgh, EH16 4SA, UK. Cardiothoracic Surgery Department, Leeds General Infirmary, Leeds, LS1 3EX, UK.

Published: 16 December 2015

doi:10.1186/1749-8090-10-S1-A201

Cite this article as: Papaspyros et al:: Surgical ergonomics - Analysis of technical skills, simulation models and assessment methods. Journal of Cardiothoracic Surgery 2015 10(Suppl 1):A201.
Submit your next manuscript to BioMed Central and take full advantage of:

- Convenient online submission

- Thorough peer review

- No space constraints or color figure charges

- Immediate publication on acceptance

- Inclusion in PubMed, CAS, Scopus and Google Scholar

- Research which is freely available for redistribution
() Biomed Central 